\title{
O USO DE CORPORA COMPARÁVEIS BILÍNGUES COMO SUBSÍDIO PARA A TRADUÇÃO DE COLOCAÇÕES
}

\author{
THE USE OF COMPARABLE BILINGUAL CORPORA AS A RESOURCE FOR \\ TRANSLATING COLLOCATIONS
}

\author{
(a) \\ Miriam Angel GOLDSCHMIDT ${ }^{1}$ \\ Universidade Federal de Pelotas \\ Roberta Rego RODRIGUES ${ }^{2}$ \\ Universidade Federal de Pelotas \\ Marisa Helena DEGASPERI ${ }^{3}$ \\ Universidade Federal de Pelotas
}

\begin{abstract}
Resumo: Este trabalho visa a oferecer mais uma metodologia e uma ferramenta de pesquisa capazes de auxiliar o tradutor na prática tradutória envolvendo colocações. Utilizando a metodologia da Linguística de Corpus aplicada aos Estudos da Tradução, esta pesquisa analisa a possibilidade da utilização de um corpus comparável bilíngue, em espanhol e português, como uma ferramenta de auxílio à tradução de colocações nesse par de línguas. Para tanto, foram compilados dois subcorpora, ambos compostos por textos jornalísticos produzidos originalmente em espanhol e português (não traduzidos). Do primeiro subcorpus, foram extraídas as possíveis colocações de tipo verbal e adjetivo baseadas nos 30 substantivos mais frequentes, e, no segundo, foram validadas as traduções dessas colocações, realizadas pelas autoras deste trabalho, com vistas a verificar seu uso na língua corrente. Identificaramse, no subcorpus em língua espanhola, 63 colocações, as quais foram traduzidas ao português e validadas no subcorpus nessa língua. Obteve-se um percentual de validação de $71,42 \%$ para as colocações verbais; $57,14 \%$ para as colocações adjetivas substantivo + adjetivo, e $60,71 \%$ para as de ordem adjetivo + substantivo. O percentual de validação atingido foi considerado bastante alto para as duas categorias, corroborando, dessa maneira, a hipótese de que, se o tradutor fizer uso de corpora comparáveis bilíngues nesse par de línguas, poderá traduzir as colocações com mais propriedade. Sugere-se que o tradutor, então, poderia compilar seus próprios corpora comparáveis, adequados à sua área de trabalho, para realizar pesquisas lexicais, o que pode auxiliá-lo no enfrentamento das dificuldades impostas pela escassez de materiais de consulta nesse par de línguas.
\end{abstract}

Palavras-chave: Estudos da Tradução. Linguística de Corpus. Colocações.

\begin{abstract}
This paper aims to offer an additional methodology and a research tool able to help the translator translate collocations. By using Corpus-based Translation Studies, this paper analyses the possibility of using a comparable bilingual corpus, in Spanish and in Portuguese, as an aid tool to the translation of collocations in this language pair. Two subcorpora of non-translated journalistic texts were compiled for making the analysis possible. The probable verbal and adjectival collocations were extracted from the first subcorpus in Spanish based on the 30 more most frequent nouns. The translation of these collocations made by the authors of this paper were validated in the second subcorpus in Portuguese with a view to verify its use in the current language. Sixty-three collocations were identified in the Spanish subcorpus, which were translated to Portuguese and validated in the subcorpus of this language. A percentage of validation of $71,42 \%$ was obtained when it comes to verbal collocations; $57,14 \%$ when it comes to adjectival collocations (noun + adjective), and 60,72\% when it comes to adjective + noun. The percentage of validation was considered quite high for the two categories, which corroborates the hypothesis that if the translator uses comparable bilingual corpora he will be able to translate collocations more effectively. It is suggested that the translator could compile his own comparable corpora,
\end{abstract}

GOLDSCHMIDT, RODRIGUES, DEGASPERI . O uso de corpora comparáveis bilíngues como subsídio para a tradução de colocações.

Belas Infiéis, v. 6, n. 1, p. 09-24, 2017. 
adequate for his work area, to do lexical research. This can help him to face the difficulties imposed by the shortage of reference material in this language pair.

Keywords: Translation Studies. Corpus Linguistics. Collocations.

\section{Introdução}

O termo colocação, introduzido por J.R. Firth em 1957, refere-se à combinação de palavras normalmente utilizada em uma dada língua (BUSSMANN, 2006; HATIM e MUNDAY, 2004). De acordo com Baker (2006), cada idioma apresenta suas colocações próprias, que nem sempre equivalem às exatas colocações de outro. Assim, ao traduzir-se de uma língua à outra, enfrenta-se o problema de encontrar os termos mais usuais da língua de chegada e não mesclá-los com os da língua de partida, pois, como observado por Tagnin (2002), é a correta utilização desses termos que oferece naturalidade a uma língua.

O tema das colocações é amplamente tratado em bibliografia de língua inglesa, tendose conhecimento de muitos trabalhos e obras lexicográficas nesse idioma ${ }^{4}$. No entanto, ainda são poucos os estudos dedicados a esta área em língua espanhola e em língua portuguesa. Dessa forma, ao trabalhar com esse par de línguas, o tradutor normalmente se vê com dificuldades para decidir qual a melhor seleção lexicográfica, devido à escassez de materiais de consulta.

Este estudo propõe-se a estudar o tema das colocações sob a ótica da tradução, complementando a abordagem habitualmente empregada que visa ao ensino e à aprendizagem de línguas. Espera-se que este trabalho possa contribuir para os Estudos da Tradução ao propor mais uma metodologia e uma ferramenta de pesquisa capazes de auxiliar o tradutor a encontrar soluções e facilitar o trabalho da tradução das colocações.

O objetivo deste trabalho é verificar a utilidade do uso de corpora linguísticos como ferramentas de apoio à tradução. Especificamente, analisa-se a possibilidade do uso de corpora comparáveis bilíngues para a validação de traduções de colocações lexicais que tenham um substantivo como base entre o par de línguas espanhol-português. Para tanto, foi feita a identificação das prováveis colocações desse tipo através de pesquisa com corpus em língua espanhola, a tradução dessas estruturas à língua portuguesa e sua posterior validação em um corpus em língua portuguesa por meio do uso da ferramenta gratuita de manipulação de corpus AntConc, de modo a constatar sua utilização na língua natural e corrente.

Espera-se também que, se o tradutor fizer uso de corpora comparáveis bilíngues para a validação de traduções de colocações lexicais entre o par de línguas espanhol-português, ele 
poderá beneficiar-se, no que diz respeito à qualidade das traduções, e esta será uma maneira de suprir, em parte, a falta de material lexicográfico no par de línguas mencionado.

\section{Colocações}

O termo colocação designa combinações entre palavras que desenvolveram uma relação semântica baseada em sua coocorrência frequente (BUSSMANN, 2006). Tagnin (2002) afirma que existem colocações em todas as línguas, e é através de sua utilização que se dá a sonoridade natural do idioma. Segundo a autora (2002, p. 192), "grande parte da língua é formada de partes pré-fabricadas, de expressões prontas, das chamadas unidades fraseológicas, unidades que não precisam ser geradas a cada vez que são empregadas”. São exemplos de colocações em língua portuguesa combinações como disparar um alarme, fiel escudeiro, mentira deslavada, chorar copiosamente $^{5}$.

Segundo Allegro et al. (2010), as colocações subdividem-se em duas grandes áreas: as colocações gramaticais, combinações entre um item lexical e outro gramatical, também denominadas coligações; e as colocações lexicais, a união sintagmática entre dois lexemas, de interesse neste trabalho.

De acordo com Hausmann (1985, apud TAGNIN, 2002), as colocações são formadas por não mais que duas palavras, sendo uma delas a base e a outra o colocado - a base é a palavra de maior carga semântica, e o colocado é a palavra que a acompanha, cuja classe gramatical definirá o tipo de colocação. Tagnin (2005) afirma que as colocações representam combinações recorrentes de palavras, que podem ser bastante restritas - como no caso de velha coroca, em que o adjetivo coroca dificilmente aparece sem estar combinado com velha - ou flexíveis, mas, neste caso, a combinação geralmente se restringe a um mesmo campo semântico. Essas estruturas são aprendidas naturalmente pelos falantes de uma língua e utilizadas por eles de forma espontânea, e são, portanto, convenções da língua (TAGNIN, 2002).

\subsection{Colocações e dificuldades de tradução}

Tagnin (2002) estabelece o conceito de tradutor ingênuo, cunhado a partir da noção de falante ingênuo, proposta por Fillmore (1979 apud TAGNIN, 2002, p. 191), que corresponde ao "aprendiz de língua estrangeira que desconhece as convenções da língua". Dessa forma, segundo a linguista, o tradutor ingênuo é o profissional que, ao traduzir, ignora a importância dessas estruturas ou as desconhece. Essa ingenuidade do tradutor mencionada pela autora pode

GOLDSCHMIDT, RODRIGUES, DEGASPERI . O uso de corpora comparáveis bilíngues como subsídio para a tradução de colocações.

Belas Infiéis, v. 6, n. 1, p. 09-24, 2017. 
concentrar-se tanto no âmbito da compreensão quanto no da produção. No que diz respeito à compreensão, o tradutor pode não entender expressões idiomáticas, fórmulas discursivas convencionalizadas e referências humorísticas resultantes da manipulação de estruturas convencionalizadas. No quesito produção, o tradutor pode ter problemas ao não ser capaz de encontrar soluções naturais por ater-se demasiadamente ao texto fonte (TAGNIN, 2002). Segundo esta autora, o tradutor

[...] pode não se dar conta de que, dentro de uma gama de formas gramaticalmente possíveis, há certas formas que têm uma probabilidade maior de ocorrerem. Caso o tradutor selecione uma dessas formas possíveis em detrimento da mais provável, produzirá uma tradução não natural, não fluente. (TAGNIN, 2002, p. 193)

Hatim e Mason (1990) afirmam que encontrar as colocações adequadas na língua alvo da tradução sempre foi um dos maiores problemas com o qual o tradutor se depara. Segundo os autores, mesmo tradutores experientes podem sofrer interferência de sua língua fonte e produzir colocações que soem artificiais na língua alvo. Aqui, parte-se do pressuposto de que uma tradução bem-sucedida soe natural na língua alvo, ou, nas palavras de Nida e Taber (1969 apud IBRAHIM, 2003, p. 25), "a melhor tradução é aquela que não parece uma tradução"6.

Baker (2006, p. 63) aponta que, "assim como palavras individuais, os padrões colocacionais são portadores de significado e podem ser específicos de uma cultura. Esses fatores, aliados à sua natureza arbitrária, suscitam numerosas armadilhas e problemas em tradução"7. Na mesma perspectiva, Tagnin (2002) afirma que a maioria dos problemas e das dificuldades decorrentes da tradução de colocações advém da não existência de complexidade em sua compreensão, pois seu significado geralmente é inteligível a partir da soma das palavras que as compõem, e, por isso, muitas vezes passam despercebidas. Contudo, no momento de sua produção, não existe realmente uma obviedade para identificar-se a colocação adequada, já que essas estruturas não são aprendidas de forma consciente e, sim, a partir da prática (TAGNIN, 2002).

\section{Linguística de Corpus e Estudos da Tradução baseados em corpora}

Segundo Berber Sardinha (2004), a Linguística de Corpus é o campo da Linguística que trata da coleta e exploração de corpora por meio de análises empíricas extraídas por computador. É descrita como uma metodologia para o estudo da língua, que permite descrever a língua e verificar hipóteses, sempre em interface com teorias da língua (McENERY, 2014;

GOLDSCHMIDT, RODRIGUES, DEGASPERI . O uso de corpora comparáveis bilíngues como subsídio para a tradução de colocações.

Belas Infiéis, v. 6, n. 1, p. 09-24, 2017. 


\section{LEECH, 2014).}

De acordo com Berber Sardinha (2004), o corpus linguístico legível por computador é o ponto central da Linguística de Corpus atual. Em citação a Sinclair (1991), Munday (2012) afirma que a rápida evolução da informática tornou possível a criação de corpora eletrônicos formados por textos em língua natural (não produzidos automaticamente por computador), passíveis de processamento e análise computadorizada para a pesquisa de padrões estruturais e lexicais.

Baker (1995) já previa que os estudos baseados em corpora ganhariam espaço nos Estudos da Tradução, principalmente no estudo de textos técnicos e científicos. Para a autora, a implementação dessa metodologia poderia contribuir para satisfazer a necessidade de um método mais rigoroso em áreas aplicadas dos Estudos da Tradução, tais como cursos de Tradução e de Crítica da Tradução, além de aprofundar a teorização sobre o fenômeno da tradução.

Vários autores, como Tagnin $(2002$, 2007) e Varantola (2002), sugerem a utilização de corpora linguísticos como ferramentas de apoio à tradução, pois, como mencionado por Varantola (2002, p. 180), “o corpus destaca convenções terminológicas, oferece ao escritor vocabulário periférico adicional e sugere formas idiomáticas de expressar ideias ${ }^{8 \%}$. Segundo a autora, o tradutor seria capaz de compilar corpora linguísticos e utilizá-los conforme sua necessidade, sendo uma maneira de suprir a escassez de recursos lexicográficos em certas áreas, certos pares de línguas e certas estruturas linguísticas (VARANTOLA, 2002).

De acordo com Xiao (2014a), os tipos de corpus normalmente utilizados em pesquisas baseadas em corpus no âmbito dos Estudos da Tradução são os corpora multilíngues, que, segundo a classificação do autor, podem ser divididos em comparáveis e paralelos. Os corpora paralelos são aqueles compostos por textos originais e suas traduções, enquanto corpora comparáveis são aqueles que contêm textos originais ou traduzidos de um mesmo tipo ou gênero em uma, duas ou mais línguas.

Xiao (2014b) lembra que se deve observar que cada um dos tipos de corpus serve ao seu próprio propósito e possui suas próprias características. O linguista explica que corpora paralelos são utilizados na construção de sistemas de tradução automática, de dicionários bilíngues e de memórias de tradução (em programas de tradução assistida por computador, as chamadas ferramentas CAT). De acordo com Xiao (2014b), esse tipo de corpus torna-se útil para pesquisa de equivalentes em tradução, uma vez que neles se pode comparar o texto original 
com sua tradução. Entretanto, por conter textos traduzidos, podem estar presentes ali exemplos de "tradutês", dificultando a realização de estudos contrastivos entre línguas. São também utilizados em pesquisas linguísticas com o objetivo de mostrar como uma ideia ou conceito é traduzido para outro idioma.

Segundo Xiao (2014b), os corpora comparáveis, por sua vez, podem ser também utilizados em pesquisas em tradução, auxiliando o tradutor a melhor entender determinada área de seu campo de tradução e aprimorando a qualidade da tradução em termos de fluência, expressões idiomáticas, correta aplicação de terminologia, colocações, etc. Baker (1995) afirma que esse tipo de corpus é proveitoso para os Estudos da Tradução, pois permite observar fenômenos linguísticos em seu ambiente natural tanto na língua fonte como na língua alvo, ao contrário do que acontece no corpus supracitado, em que se analisam também textos traduzidos, vinculados aos originais. De acordo com a autora, esse tipo de corpus é especialmente útil porque permite observar padrões e convenções que ocorrem naturalmente na língua alvo. Nesse sentido, segundo Xiao, (2014b) seria possível que o tradutor compilasse corpora personalizados, de acordo com sua necessidade, área de atuação e pares de línguas com que 14 trabalha. Essa atividade poderia contribuir para uma maior qualidade na tradução, visto que teria exemplos confiáveis e reais em que se basear.

No âmbito da Linguística de Corpus aplicada à prática de tradução, também Varantola (2002) e Tagnin (2005) sugerem a construção de corpora temporários ou permanentes pelo próprio tradutor, de acordo com os objetivos de sua pesquisa, constituídos por textos retirados da internet ou de materiais de consulta em formato digital. De acordo com as autoras, esses corpora são bastante flexíveis e podem ser construídos de maneira a adaptarem-se às necessidades de cada tradutor e aos resultados de que necessita. A partir da compilação de um corpus desse tipo, o tradutor poderia explorá-lo com ferramentas eletrônicas específicas para a manipulação de textos, podendo coletar, assim, um grande número de dados, identificando neles o que for mais útil para sua necessidade (TAGNIN, 2007).

Segundo Varantola (2002), um corpus temporário não precisa ser elaborado de maneira tão técnica como são os corpora normalmente utilizados para pesquisa em Linguística de Corpus. Os textos do corpus, após seu uso, podem ser descartados, ou refinados de forma a serem utilizados como parte de um corpus maior. A autora verificou, em estudo conduzido com tradutores em formação, que uma das aplicações para os corpora temporários ou descartáveis seria a validação de termos em traduções, principalmente no caso de versões. Nesses casos, de 
acordo com Varantola (2002), ao pesquisar em dicionários, o tradutor pode se deparar com dois ou mais termos sendo oferecidos como equivalentes e sinônimos, mas que muitas vezes são utilizados em contextos diferentes. Esse tipo de sentido pode ser captado através de pesquisa com corpora, visto que se torna possível observar os vários contextos em que as palavras estão inseridas. $\mathrm{O}$ fato de poder comprovar o uso real de uma palavra oferece mais confiança ao tradutor no momento de fazer a escolha lexical (VARANTOLA, 2002).

Ao combinar fontes de pesquisa estruturadas e sistemáticas com corpora versáteis e flexíveis, Varantola (2002) acredita que o tradutor possa obter mais benefícios e qualidade em suas traduções.

\section{Constituição e análise do corpus}

Para a investigação realizada neste trabalho, optou-se pela construção de um corpus comparável bilíngue, constituído, como definido por Frankenberg-Garcia (2006), por dois subcorpora de textos produzidos originalmente nas línguas A e B (não traduzidos) e de mesmo gênero textual e tipo. Esse tipo de corpus é considerado pela autora como funcional para pesquisa terminológica no dia a dia do tradutor. O subcorpus em língua espanhola foi compilado para a extração das prováveis colocações mais frequentes em tal língua, e o subcorpus em língua portuguesa, para a validação da tradução dessas colocações.

O subcorpus em língua espanhola está constituído por textos produzidos originalmente neste idioma e retirados da edição online de quatro jornais de circulação nacional dos países hispanofalantes do Mercosul. Foram escolhidos os jornais El País, do Uruguai; Clarín, da Argentina, ABC Color, do Paraguai; e El Universal, da Venezuela. Optou-se, neste trabalho, pela técnica de download manual referida por McEnery (2014).

Da mesma forma, o corpus de língua portuguesa está formado por textos originalmente produzidos neste idioma e extraídos de quatro jornais brasileiros de grande representação em suas respectivas regiões: O Estado de São Paulo, Zero Hora (Porto Alegre), Folha de São Paulo e Estado de Minas. Ambos os corpora totalizaram em torno de cem mil tokens, isto é, ocorrências de elementos linguísticos.

O corpus em língua espanhola foi carregado no programa de manipulação de corpus AntConc (versão 3.4.4w). Estipulou-se que seriam identificadas todas as colocações de tipo verbal e adjetivo provenientes dos trinta substantivos mais frequentes do subcorpus em língua

GOLDSCHMIDT, RODRIGUES, DEGASPERI . O uso de corpora comparáveis bilíngues como subsídio para a tradução de colocações.

Belas Infiéis, v. 6, n. 1, p. 09-24, 2017. 
espanhola. A lista com os substantivos foi produzida por meio da utilização da função Word list, que apresenta uma lista das palavras por ordem de frequência de aparição no corpus.

Para a verificação das estruturas recorrentes, foi utilizada, em primeiro lugar, a ferramenta Clusters, a qual permite que se observem padrões de recorrência de determinada palavra com outras que apareçam imediatamente à sua esquerda ou direita. Segundo Anthony (2014), essa ferramenta é especialmente útil quando se deseja encontrar padrões de recorrência de duas ou três palavras, como o são as colocações.

Baseando-se nos resultados obtidos pela ferramenta Clusters, procedeu-se à análise dos contextos de ocorrência das estruturas identificadas com a utilização da ferramenta Concordance. Segundo Tagnin (2005), ferramentas que apresentem os resultados na forma de linhas de concordância, ou seja, exibindo a palavra em que se tem interesse no centro da tela, dentro de seu contexto natural de ocorrência, são as que melhor permitem a observação de estruturas recorrentes. Os padrões de recorrência podem ser verificados a partir da observação das palavras que ocorrem à direita ou à esquerda da palavra em questão.

A partir da lista de colocações obtida pela pesquisa, procedeu-se à tradução desses 16 sintagmas por seus correspondentes usuais em língua portuguesa, realizada pelas autoras do trabalho. Traduziram-se não apenas as colocações selecionadas, mas frases em que estivessem presentes.

De posse das traduções das estruturas, foi feita sua validação no subcorpus de textos em português, ou seja, foi verificado seu uso real em língua portuguesa, através dos contextos de ocorrência neste subcorpus.

\section{Resultados e discussão}

Com a utilização da metodologia descrita na seção anterior, foram encontradas e analisadas 63 possíveis colocações, dos tipos adjetivo e verbal, conforme a terminologia referida por Tagnin (2005) e aplicada a este trabalho.

\subsection{Colocações verbais}

Analisou-se um total de quatorze colocações verbais, categoria em que estão incluídas as colocações formadas por verbo + substantivo e as formadas por verbo + preposição + substantivo, obtendo-se um percentual de $71,42 \%$ de validação de suas traduções no subcorpus em português. 
A utilização de corpus para a validação de colocações mostrou-se bastante proficiente para este tipo de colocação, pois, das quatorze compiladas no subcorpus em espanhol, apenas a tradução de quatro delas não pôde ser validada em português. Este resultado se mostra relevante, uma vez que, segundo Tagnin (2005), este tipo de colocação representa uma dificuldade inclusive para falantes nativos.

$\mathrm{Na}$ tabela a seguir, podem ser observadas as colocações verbais encontradas e suas respectivas traduções, além de sua frequência de coaparição em ambos os subcorpora.

Tabela 1 - Colocações verbais.

\begin{tabular}{|c|c|c|c|}
\hline Colocação em espanhol & Frequência & Tradução ao português & Frequência \\
\hline aprobar el proyecto & 2 & aprovar o projeto & 6 \\
\hline brindar información & 5 & fornecer informações & 0 \\
\hline conocer la situación & 2 & conhecer a situação & 0 \\
\hline darse cuenta & 5 & dar-se conta & 1 \\
\hline formar parte & 11 & fazer parte & 13 \\
\hline hacer años & 14 & haver anos & 11 \\
\hline hacer meses & 12 & haver meses & 10 \\
\hline hacer frente & 2 & fazer frente/enfrentar & $0 / 10$ \\
\hline llegar a tiempo & 4 & chegar a tempo & 0 \\
\hline sancionar la ley & 2 & sancionar a lei & 2 \\
\hline otorgar poderes & 2 & outorgar poderes & 0 \\
\hline tener en cuenta & 11 & $\begin{array}{l}\text { levar em consideração/ } \\
\text { considerar }\end{array}$ & $1 / 13$ \\
\hline tener trabajo & 4 & ter trabalho & 2 \\
\hline tomar(se) en cuenta & 3 & levar em conta/ considerar & $10 / 13$ \\
\hline
\end{tabular}

No que diz respeito às traduções dos contextos contendo colocações verbais, chama-se a atenção para as colocações tener en cuenta e tomar(se) en cuenta. Ambas as estruturas podem ser traduzidas por um equivalente colocacional em língua portuguesa, que, conforme pode ser

$\overline{\text { GOLDSCHMIDT, RODRIGUES, DEGASPERI . O uso de corpora comparáveis bilíngues como subsídio para a }}$ tradução de colocações.

Belas Infiéis, v. 6, n. 1, p. 09-24, 2017. 
observado na tabela, pôde ser validado no subcorpus português. No entanto, da mesma maneira, as duas colocações apresentam um equivalente verbal, o verbo "considerar", que, no subcorpus em português apresentava 47 ocorrências, das quais treze expressavam significado equivalente a tener en cuenta ou tomar(se) en cuenta. Por essa razão, o verbo foi considerado como equivalente das colocações supracitadas. Assim, considerando-se a existência de mais de uma possibilidade, sem prejuízo ao significado, ficaria a critério do tradutor optar por uma tradução ou outra.

\subsection{Colocações adjetivas}

As colocações adjetivas encontradas foram subdivididas de acordo com a ordem de aparição do adjetivo em relação ao substantivo. Foram analisadas 21 colocações substantivo + adjetivo, com um percentual de 57,14\% de validação; e 28 colocações adjetivo + substantivo, com um percentual de $60,71 \%$ de validação. Nesta categoria, além da confirmação ou não das estruturas traduzidas, foi possível também identificar usos paralelos de determinadas colocações.

18 Na tabela a seguir, podem ser observadas as colocações adjetivas substantivo + adjetivo encontradas e suas respectivas traduções, além de sua frequência de coaparição em ambos os subcorpora.

Tabela 2 - Colocações substantivo + adjetivo.

\begin{tabular}{lcllc}
\hline Colocação em espanhol & Frequência & Tradução ao português & Frequência \\
\hline año pasado & 12 & ano passado & 44 \\
gobierno nacional & 8 & governo nacional & 0 \\
ministerio público & 12 & ministério público & 58 \\
país desarrollado & 2 & país desenvolvido & 0 \\
parte médico & 4 & laudo médico & 0 \\
partido político & 4 & partido político & 2 \\
poder ejecutivo & 11 & poder executivo & 1 \\
poder judicial & 6 & poder judiciário & 2 \\
poder legislativo & 3 & poder legislativo & 1
\end{tabular}

GOLDSCHMIDT, RODRIGUES, DEGASPERI . O uso de corpora comparáveis bilíngues como subsídio para a tradução de colocações.

Belas Infiéis, v. 6, n. 1, p. 09-24, 2017. 


\begin{tabular}{llll} 
poder especial & 5 & poder especial & 0 \\
poder público & 3 & poder público & 0 \\
policía federal & 2 & polícia federal & 10 \\
policía técnica & 4 & polícia técnica & 0 \\
seguridad alimentaria & 2 & segurança alimentar & 0 \\
seguridad social & 10 & previdência social & 1 \\
situación financiera & 2 & situação financeira & 1 \\
situación política & 2 & situação política & 0 \\
situación procesal & 4 & situação processual & 0 \\
trabajo comunitario & 4 & serviço comunitário & 1 \\
tiempo completo & 6 & tempo integral & 1 \\
tiempo real & 2 & tempo real & 2 \\
\hline
\end{tabular}

O aspecto da convencionalidade das colocações (TAGNIN, 2002, 2005; ALLEGRO et al., 2010) pode ser bem observado no caso das colocações adjetivas. Assim como nas demais categorias, muitas vezes uma combinação de palavras do tipo adjetivo acaba por se cristalizar de forma bastante semelhante em dois idiomas, como é o caso de año pasado x "ano passado" e tiempo real x "tempo real", em que ambos os termos possuem equivalentes basicamente literais em português e espanhol. No entanto, por várias razões, existem colocações em que um ou os dois termos da colocação apresentam um equivalente menos óbvio. Comparando os resultados encontrados neste trabalho, é possível verificar que há casos em que o substantivo é mantido, havendo mudanças no adjetivo convencionado (tiempo completo x tempo integral); e, em outros, é o adjetivo que permanece, sendo o substantivo o termo convencionado (parte médico x laudo médico, trabajo comunitario x serviço comunitário).

São principalmente essas estruturas, que possuem equivalência num todo, mas não palavra por palavra, que podem produzir dificuldades e ocasionar problemas na tradução de colocações, especialmente em línguas tão próximas como o português e o espanhol.

A tabela seguinte expõe as colocações adjetivas adjetivo + substantivo encontradas e suas respectivas traduções, assim como sua frequência de coaparição em ambos os subcorpora.

GOLDSCHMIDT, RODRIGUES, DEGASPERI . O uso de corpora comparáveis bilíngues como subsídio para a tradução de colocações.

Belas Infiéis, v. 6, n. 1, p. 09-24, 2017. 


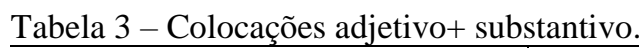

\begin{tabular}{|c|c|c|c|}
\hline Colocação em espanhol & Frequência & Tradução ao Português & Frequência \\
\hline buena parte & 3 & boa parte & 5 \\
\hline cada vez & 12 & cada vez & 7 \\
\hline gran parte & 6 & grande parte & 4 \\
\hline grave estado & 4 & estado grave & 3 \\
\hline mayor parte & 3 & maior parte & 6 \\
\hline misma persona & 2 & mesma pessoa & 0 \\
\hline mucho tiempo & 3 & muito tempo & 0 \\
\hline nueva ley & 6 & nova lei & 0 \\
\hline otra vez & 7 & outra vez & 0 \\
\hline otro país & 6 & outro país & 4 \\
\hline poco tiempo & 5 & pouco tempo & 1 \\
\hline pocos días & 5 & poucos dias & 0 \\
\hline primer lugar & 6 & primeiro lugar & 2 \\
\hline primer partido & 2 & primeiro jogo & 0 \\
\hline primera vez & 15 & primeira vez & 11 \\
\hline primeras horas & 6 & primeiras horas & 0 \\
\hline primeros lugares & 2 & primeiros lugares & 1 \\
\hline próximas horas & 3 & próximas horas & 0 \\
\hline próximo año & 5 & próximo ano & 1 \\
\hline próximos días & 4 & próximos dias & 4 \\
\hline segunda vez & 4 & segunda vez & 0 \\
\hline segundo tiempo & 3 & segundo tempo & 0 \\
\hline todo el tiempo & 5 & o tempo todo & 1 \\
\hline última vez & 3 & última vez & 1 \\
\hline últimas horas & 3 & última hora & 2 \\
\hline
\end{tabular}

$\overline{\text { GOLDSCHMIDT, RODRIGUES, DEGASPERI . O uso de corpora comparáveis bilíngues como subsídio para a }}$ tradução de colocações.

Belas Infiéis, v. 6, n. 1, p. 09-24, 2017. 


\begin{tabular}{lccc} 
último año & 31 & último ano & 14 \\
últimos meses & 7 & últimos meses & 4 \\
única vez & 4 & única vez & 0 \\
\hline
\end{tabular}

Na Tabela 3, destaca-se que a maioria das combinações são formadas por adjetivos não restritivos ou adjetivos graduais, ou seja, adjetivos que podem ser aplicados a toda uma classe de substantivos, não restringindo seu significado (REAL ACADEMIA ESPAÑOLA, 2010). Neste caso, estipula-se que estas estruturas sejam colocações adjetivas em razão de sua coocorrência recorrente (bastante recorrente em alguns casos), mas, devido à pouca restrição de uso desse tipo de adjetivo, é possível que essa definição não se aplique a todas as estruturas.

De igual forma, cabe ressaltar que em dois casos específicos, por exemplo, apesar de os adjetivos que se colocam com os substantivos pertencerem ao tipo não restritivo, as colocações geradas são bastante restritas. Este é o caso das colocações "primeiro tempo" e "segundo tempo", que são utilizadas para indicar as divisões de diversos esportes, em especial o futebol. Dessa forma, acabaram por tornar-se termos do esporte, e sua tradução deverá ser feita respeitando-se essa terminologia.

Outro aspecto passível de destaque é a inversão da ordem entre adjetivo e substantivo. Allegro et al. (2010) afirmam que as colocações podem apresentar ora padrões coincidentes ora padrões distintos entre duas línguas. Assim, citam-se os exemplos das colocações grave estado vs. estado grave e todo el tiempo vs. o tempo todo, em que as classes de palavras aparecem em ordem inversa em uma língua e outra, havendo sido ambas as estruturas validadas no subcorpus em português.

\section{Considerações finais}

Segundo Varantola (2002), cada vez mais são produzidos materiais de pesquisa eletrônicos, tais como dicionários e glossários, de maneira a satisfazer um público específico. No entanto, esses progressos na área lexicográfica ainda são insuficientes para atender a todas as necessidades de tradutores: ao descrever ou conceituar uma palavra, os dicionários normalmente as apresentam com pouco ou nenhum exemplo de uso em contexto, tornando impossível para o tradutor encontrar uma solução dependente de contexto; ao buscar uma palavra em um dicionário bilíngue, o tradutor está procurando por equivalentes, mas também

$\overline{\text { GOLDSCHMIDT, RODRIGUES, DEGASPERI . O uso de corpora comparáveis bilíngues como subsídio para a }}$ tradução de colocações.

Belas Infiéis, v. 6, n. 1, p. 09-24, 2017. 
quer ter certeza e segurança em sua escolha, o que muitas vezes não é fornecido pelos materiais de consulta tradicionais (VARANTOLA, 2002).

A partir da análise realizada neste trabalho, verificou-se que a utilização de um corpus comparável bilíngue mostra-se bastante útil para a validação de traduções de colocações do tipo verbal e adjetivo. Assim, ao compilar seus próprios corpora, como sugerido por Varantola (2002), adequados à sua área de trabalho, para realizar pesquisas lexicais e validar as soluções encontradas, o tradutor poderia obter auxílio no enfrentamento das dificuldades impostas pela escassez de materiais de consulta no par de línguas espanhol-português.

\section{REFERÊNCIAS BIBLIOGRÁFICAS}

ALLEGRO, Alzira L. V.; BREZOLIN, Adauri; MOBAID, Rosalind. Happy couples dicionário de colocações lexicais adjetivas: português-inglês, inglês-português. Barueri: DISAL, 2010.

ANTHONY, Laurence. AntConc: looking for clusters. Corpus Linguistics: method, analysis, interpretation. Curso online. Lancaster: Future Learn, 2014.

BAKER, Mona. Corpora in translation studies: An overview and some suggestions for future research. Target, v. 7, n. 2, p. 223-243, 1995.

In other words: a coursebook on translation. London \& New York: Routledge, 2006.

BERBER SARDINHA, Tony. Linguística de Corpus. Barueri: Manole, 2004.

BUSSMANN, Hadumod. Routledge dictionary of language and linguistics. London \& New York: Routledge, 2006. (formato e-book)

FRANKENBERG-GARCIA, Ana. Corpora e Tradução. Material didático utilizado na primeira Escola de verão da Linguateca, Módulo 3, 2006.

HATIM, Basil; MASON, Ian. Discourse and the translator. London: Longman Group UK Limited, 1990.

HATIM, Basil A.; MUNDAY, Jeremy. Translation: An advanced resource book. London \& New York: Routledge, 2004.

IBRAHIM, Yaser. The translation of collocation into Arabic problems and solutions. 2003. 335f. Tese (Doutorado). University of Leeds - Departamento de Árabe e estudos do Oriente Médio. Leeds, 2003.

LEECH, Geoffrey. A further introduction to corpus linguistics. Corpus linguistics: method, analysis, interpretation. Curso online. Lancaster: Future Learn, 2014.

GOLDSCHMIDT, RODRIGUES, DEGASPERI . O uso de corpora comparáveis bilíngues como subsídio para a tradução de colocações.

Belas Infiéis, v. 6, n. 1, p. 09-24, 2017. 
McENERY, Tony. Corpus linguistics: method, analysis, interpretation. Curso online. Lancaster: Future Learn, 2014.

MUNDAY, Jeremy. Introducing Translation Studies: Theories and Applications. London \& New York: Routledge, 2012.

REAL ACADEMIA ESPAÑOLA. Manual de la nueva gramática de la lengua española. Madrid: Espasa Libros, 2010.

TAGNIN, Stella. Os Corpora: instrumentos de auto-ajuda para o tradutor. Cadernos de Tradução, Florianópolis, v. 1, n. 9, 191-219, 2002/1.

2005.

O jeito que a gente diz: expressões convencionais e idiomáticas. São Paulo: Disal,

A Identificação de equivalentes tradutórios em corpora comparáveis. In: Anais do I Congresso Internacional da ABRAPUI. Belo Horizonte. 2007.

VARANTOLA, Krista. Disposable corpora as intelligent tools in translation. Cadernos de Tradução, Florianópolis, v. 1, n. 9, 171-189, 2002/1.

XIAO, Richard. Introducing comparable and parallel corpora. Corpus linguistics: method, analysis, interpretation. Curso online. Lancaster: Future Learn, 2014a.

The use of comparable and parallel corpora. Corpus linguistics: method, analysis, interpretation. Curso online. Lancaster: Future Learn, 2014b.

RECEBIDO EM: 06/01/2017

ACEITO EM: 10/09/2017

PUBLICADO EM: Junho de 2017

\footnotetext{
${ }^{1}$ Miriam Angel GOLDSCHMIDT - Bacharel em Letras Tradução Espanhol/Português (2015) pela Universidade Federal de Pelotas (UFPel). Atua como professora de inglês e espanhol, tradutora e revisora de textos. Pelotas, Rio Grande do Sul, Brasil.

Lattes: http://lattes.cnpq.br/5147122694198568 E-mail: miriam.golds01@ @mail.com

${ }^{2}$ Roberta Rego RODRIGUES - Possui graduação em Letras - Licenciatura em Inglês (2003) pela Universidade Federal de Minas Gerais (UFMG). Mestre (2005) e Doutora (2010) em Linguística Aplicada mesma universidade. Atualmente é professora adjunta do Centro de Letras e Comunicação da Universidade Federal de Pelotas (UFPel) com atuação na Área de Tradução (Inglês/Português/Inglês). Pelotas, Rio Grande do Sul, Brasil. Lattes: http://lattes.cnpq.br/6281175549996840 E-mail: betareseau@gmail.com

3 Marisa Helena DEGASPERI - Possui graduação em Letras — Licenciatura em Português (1992) pela Universidade Federal do Espírito Santo (UFES) e mestrado em Educação (2002) pelo Instituto Superior Pedagógico Enrique José Varona, Cuba. Doutorou-se em Linguística e Letras pela Pontifícia Universidade Católica do Rio Grande do Sul (PUCRS) em 2009. Atualmente é professora adjunta do Centro de Letras e Comunicação da Universidade Federal de Pelotas (UFPel) com atuação na Área de Tradução (Espanhol/Português/Espanhol). Pelotas, Rio Grande do Sul, Brasil.

Lattes: http://lattes.cnpq.br/6891029117610519 E-mail: mhdufpel2012@gmail.com
}

GOLDSCHMIDT, RODRIGUES, DEGASPERI . O uso de corpora comparáveis bilíngues como subsídio para a tradução de colocações.

Belas Infiéis, v. 6, n. 1, p. 09-24, 2017. 
${ }^{4}$ São exemplos o Oxford Collocations Dictionary, da Oxford University Press; o Longman Collocations and Thesaurus, da Editora Pearson; e o Happy Couples: dicionário de colocações lexicais adjetivas (inglês-português/ português-inglês), da editora Disal.

${ }_{6}^{5}$ Exemplos de Allegro et al. (2010).

6 “(...) the best translation does not sound like a translation” (tradução nossa).

7 "Like individual words, collocational patterns carry meaning and can be culture-specific. This, in addition to their largely arbitrary nature, gives rise to numerous pitfalls and problems in translation" (tradução nossa).

8 "The corpus highlights the terminological conventions, it gives writers additional peripheral vocabulary and suggests idiomatic ways of expressing ideas" (tradução nossa). 